\title{
Mapping of the lipid-binding and stability properties of the central rod domain of human dystrophin
}

\author{
Sébastien Legardinier ${ }^{\#}$, Céline Raguénès-Nicol ${ }^{\#}$, Christophe Tascon ${ }^{\#}$, Chantal Rocher ${ }^{\#}$, Serge \\ Hardy $^{\S}$, Jean-François Hubert ${ }^{\#}$ and Elisabeth Le Rumeur ${ }^{\# 1}$ \\ From ${ }^{\#}$ UMR CNRS 6026 Interactions cellulaires et moléculaires, équipe RMN et Interactions Lipides- \\ Protéines. ${ }^{\S}$ UMR CNRS 6061 Génétique et développement. Université Rennes1. IFR 140. Faculté de \\ Médecine, CS 34317, 35043 Rennes Cedex, France.
}

Running title: Dystrophin rod domain lipid-binding and stability properties

Address for correspondence: Elisabeth Le Rumeur, Université Rennes1, UMR CNRS 6026, RMNILP, IFR 140, Faculté de Médecine, CS 34317, 35043 Rennes Cedex, France. Phone: (33) 2232346 27; Fax: (33) 2232346 06; Email: elisabeth.le-rumeur@univ-rennes1.fr

\begin{abstract}
Dystrophin is a cytoskeletal protein that confers resistance to the sarcolemma against the stress of contraction-relaxation cycles by interacting with cytoskeletal and membrane partners. Apart from several proteins, membrane phospholipids are a partner of the central rod domain made up of 24 spectrin-like repeats, separated into sub-domains by four hinges. We previously showed that repeats 1 to 3 bind to membrane anionic phospholipids, while repeats 20 to 24 are not able to do so. We focus here on the phospholipid-binding properties of the major part of the central rod domain, namely the sub-domain delineated by hinges 2 and 3 comprising 16 repeats ranging from repeat 4 to 19 (R4-19). We designed and produced multirepeat proteins comprising three to five repeats and report their lipid-binding properties as well as their thermal stabilities. When these proteins are mixed with liposomes including the anionic lipid phosphatidylserine, they form stable protein-vesicle complexes as determined by gel filtration chromatography. The absence of an anionic lipid precludes the formation of such complexes. Spectroscopic analyses by circular dichroism and tryptophan fluorescence show that, while the alpha helical secondary structures are not modified by the binding, protein trans-conformation leads to the movement of tryptophan residues into more hydrophobic environments. In addition, the decrease in the molar ellipticity ratio at $222 / 208 \mathrm{~nm}$ as observed by circular dichroism indicates that lipid-binding reduces the interhelical interactions of multirepeat proteins, thus suggesting partly "opened" coiled-coil structures. Combining these results with data from our previous studies, we propose a new model of the dystrophin molecule lying along the membrane bilayer, in which the two subdomains R1-3 and R4-19 interact with lipids and F-actin, while the distal sub-domain R20-24 does not exhibit any interaction. These lipid-binding domains should thus maintain a structural link between cytoskeletal actin and sarcolemma via the membrane phospholipids.
\end{abstract}




\section{Introduction}

Dystrophin is a long filamentous protein essential for skeletal muscle function as indicated by the lethal pathophysiology associated with its deficiency, namely the Duchenne muscular dystrophy. ${ }^{1}$ Its primary function is likely to provide a mechanical reinforcement of the sarcolemma which opposes the stress encountered by contraction and elongation of the muscle fibres at work. ${ }^{2}$ For this purpose, it appears essential that dystrophin should interact with several membrane and cytoskeletal partners. Several partners have been identified, including the proteins of the dystrophin-glycoprotein complex ${ }^{3}$, in particular $\beta$-dystroglycan ${ }^{4}$ which interacts with the Cysteine-rich region of the dystrophin located between the stabilizing sub-domain R20-24 of the rod domain and the C-terminal end of the molecule. Cytoskeletal actin interacts with the dystrophin molecule via two actin-binding domains, ABD1 and $\mathrm{ABD} 2$, situated at the N-terminal end and at the centre of the dystrophin rod domain (repeats R11-15) respectively.; ${ }^{5 ; 6}$ Membrane anionic phospholipids interact with the repeat 2 of the long central rod domain. ${ }^{7 ; 8}$ Such lipid-binding properties of the rod domain may be essential in providing mechanical stability to the sarcolemma, as shown in the case of the spectrin-related cytoskeleton of the erythrocyte. ${ }^{9}$ Additionally, we previously showed that the sub-domain R1-3 consists in a first lipidbinding domain (LBD1) exhibiting strong interaction with anionic phospholipids, while the subdomain R20-24 exhibits no interaction. ${ }^{10}$ This modularity in the lipid and actin binding properties appears essential for the coordination of the function of dystrophin. However, a large part of the central rod domain has no known partner. Therefore, it is of great interest to map the entire rod domain for its potential lipid-binding properties. Such an investigation was previously carried out for the $\alpha$ and $\beta$-spectrin of the erythrocyte, ${ }^{11}$ where the authors chose to produce recombinant single-repeat proteins. Their mapping shows that three patches of three repeats interact with lipids. Early attempts by other authors to produce dystrophin single repeats were largely unsuccessful ${ }^{12 ;}{ }^{13}$, and it appears that each repeat needs to be extended by several residues at both $\mathrm{N}$ - and $\mathrm{C}$-terminal ends to obtain properly folded polypeptides. That was also our experience with repeat 23 , as reported previously. ${ }^{10}$ In the present study, we adopt an alternative strategy that enables us to produce several recombinant proteins comprising at least three repeats each. We report here the lipid-binding properties of these proteins as well as their thermal stability. Our results combined with previous studies allow us to build an overall model of lipid-binding sites within the dystrophin rod domain.

\section{Results}

\section{Design and characterization of recombinant dystrophin rod domain constructs}

To map the lipid-binding properties of the region R4-9 of the dystrophin rod domain between hinges 2 and 3, we first attempted to produce three-repeat long proteins as shown in Table 1 and Fig. 1. The two first (R4-6 and R7-9), along with one in the centre (R12-14) and the last one (R17-19), were successfully expressed, produced and purified in sufficient amounts to obtain biochemical data. After concentration and two-step purification, all proteins appeared in Coomassie blue stained 12\% polyacrylamide gels as bands at apparent molecular weights close to the theoretical values (37 to 39 $\mathrm{kDa}$ ). Protein R9-11 was difficult to obtain in sufficient amounts and at the same purity as the others, even after ion-exchange chromatography, and was moreover unstable at $4^{\circ} \mathrm{C}$. Protein $\mathrm{R} 14-16$ was obtained at very high purity, but in low amounts. We were repeatedly hindered by the disappearance of these two latter proteins during gel filtration chromatography. Therefore, to analyse the regions covering these repeats, we cloned other combinations of repeats. We successfully obtained low amounts of the three-repeat protein R10-12 and larger amounts of the four-repeat protein R14-17, the latter being designed with the same N-terminal short boundary as for R14-16. To analyse the lipidbinding properties of the actin-binding domain ABD2, ${ }^{6}$ a five-repeat R11-15 was produced with no extensions.

Far UV circular dichroism spectra display the typical features of proteins with a predominant $\alpha$-helix folding, with two well-defined minima, at 208 and $222 \mathrm{~nm}$ (Fig. 2, insets), as expected for dystrophin repeats ${ }^{13 ; 14}$ as well as for spectrin repeats. ${ }^{15 ; 16}$ The $\alpha$-helix contents estimated from the molar ellipticity values at $222 \mathrm{~nm}$ are above $57 \%$ for the three-repeat proteins R4-6, R7-9, R12-14 
and R17-19, while R10-12 and R14-16 display very low $\alpha$-helix contents of 20 and $25 \%$, respectively. R14-17 and R11-15, which have four and five repeats, display high $\alpha$-helix contents at 66 and $71 \%$, respectively. It is noteworthy that, for the first 156 residues of the human erythroid $\alpha$ spectrin, a large discrepancy was previously observed ${ }^{17}$ between the $\alpha$-helix percentages obtained from CD at $222 \mathrm{~nm}$ (using the common value of -36000 deg. $\mathrm{cm}^{2} . \mathrm{dmol}^{-1}$ for $100 \%$ helicity) compared with the more accurate results from NMR. The helicity obtained from CD is underestimated by a factor of 1.30 compared to NMR. Therefore, it is likely that the proteins studied here may have helical contents higher than the values calculated from CD measurements. However, even if we apply the ratio obtained previously ${ }^{17}$ to the very low values obtained for R10-12 and R14-16, the values would be 26 and $33 \%$ compared to 20 and $25 \%$, respectively. This implies that these two proteins have a 67 to $74 \%$ disordered structure, and thus cannot be considered as well-folded proteins.

In far-UV circular dichroism spectra, the ratio of the molar ellipticities at $222 \mathrm{~nm}$ and $208 \mathrm{~nm}$ $\left(\theta_{222} / \theta_{208}\right)$ has been used to evaluate the presence of an inter-helix association. ${ }^{18}$ In particular, the $n-\pi^{*}$ transition at $222 \mathrm{~nm}$ is responsive to the $\alpha$-helical content, while the $\pi-\pi^{*}$ excitation at $208 \mathrm{~nm}$ is sensitive to the helix axis and, therefore, to whether the $\alpha$-helix axis is interacting with another helix as in two-stranded coiled-coils. Thus, the molar ellipticity at $222 \mathrm{~nm}$ remains unchanged during an inter-helix interaction, while a decrease is observed in the molar ellipticity at $208 \mathrm{~nm}^{18 ; 19 ; 20 ; 21}$ Zhou et al. ${ }^{22}$ determined empirically that the $\theta_{222} / \theta_{208}$ ratio is equal or higher than 1 for two-stranded coiledcoils, whereas, for non-interacting helices, the ratio is lower than 1 , lying between $0.8-0.9$. In our study, the $\theta_{222} / \theta_{208}$ ratios range from 1.02 to 1.15 for the six well-folded proteins (Fig.3), strongly indicating that the helices of the proteins are associated together in coiled-coils. Therefore, as dystrophin and spectrin repeats are exclusively folded in an $\alpha$-helix, we find that six (R4-6, R7-9, R11-15, R12-14, R14-17 and R17-19) out of the eight analysed proteins with $\alpha$-helical contents higher than $50 \%$ can be considered as properly folded in an $\alpha$-helix and structured in coiled-coils. However, R10-12 and R14-16 do not satisfy the first condition and therefore do not have a coiled-coil structure. Hence, these two latter proteins are not studied in more detail here, and the present investigation of stability and potential lipid-binding properties is focused solely on the six properly folded proteins covering the entire rod domain comprised between hinges 2 and 3, except for repeat 10 .

\section{Heat-induced unfolding of multirepeat dystrophin proteins}

The heat-induced unfolding was monitored by far UV circular dichroism at $222 \mathrm{~nm}$, with proteins being exposed to increasing temperature from 15 to $85^{\circ} \mathrm{C}$. Figure 2 presents the results of heating expressed as fraction unfolded. Each solid curve represents the best fit of the experimental data in relation to Eq. 1, which describes the temperature-unfolding as a two-state process (Materials and methods). All the proteins show a two-state unfolding experimental profile, and the calculated $\mathrm{T}_{\mathrm{m}}$ values are reported in Fig.2. We can observe considerable differences in the sharpness of transitions. R7-9 shows a very broad thermal profile while by contrast R14-17 shows a very well defined transition. All the $\mathrm{T}_{\mathrm{m}}$ values appear to fall within a range from 50 to $65^{\circ} \mathrm{C}$. The protein refolding capacity upon cooling after heating was tested by heating proteins with a ramp from $15^{\circ} \mathrm{C}$ to a temperature seven degrees higher than the $T_{m}$ observed in the first data set. The two corresponding spectra are shown for each protein in Fig. 2 insets. The proteins refold only partially after heating, with the four- and five-repeat R14-17 and R11-15 refolding to a lesser extent than the three-repeat R4-6, R7-9 and R12-14. Thus, it appears that the six properly folded proteins are relatively stable, with middenaturation temperatures in the range of 50 to $65^{\circ} \mathrm{C}$.

\section{Rod domain proteins bind to anionic phospholipid vesicles and form stable protein-lipid complexes}

The lipid binding properties of the multirepeat proteins are first assessed using either size exclusion chromatography or velocity sedimentation on sucrose density gradients of proteins with or without vesicles, to separate physically the protein-vesicle complexes from free protein. Fig. 4 shows two examples of the two methods. 
Firstly, R7-9 and R17-19 are subjected to velocity sedimentation on sucrose density gradients, and the different fractions obtained are analysed with SDS-PAGE and Coomassie blue staining (Fig. 4A). While we observe a peak broadening due to diffusion in the sucrose gradient, the proteins sediment out alone as single peaks with maxima in the top fractions of the gradient (15 to 17). These fractions correspond to apparent sedimentation coefficients of $\sim 2 \mathrm{~S}$, which fit well with the monomeric state of the proteins. The vesicles alone remain on the top of the gradient, as determined by spectrometry at $345 \mathrm{~nm}$. Protein-vesicle complexes are detected as single peaks, with maxima in the bottom fractions of the gradient (3-7 or 9-13), yielding apparent sedimentation coefficients of 7 to $10 \mathrm{~S}$. Figure 4A shows that both R7-9 and R17-19 peak at the bottom of the gradient as protein-vesicle complexes, when they have been in contact with DOPC/DOPS vesicles, and in the top fractions of the gradient when they have been in contact with DOPC/DOPE vesicles. Therefore, we conclude that both proteins bind to $\mathrm{PC} / \mathrm{PS}$ but not to $\mathrm{PC} / \mathrm{PE}$.

Secondly (Fig. 4B), we analysed protein binding to lipid vesicles by size exclusion chromatography. Figure 4B shows the results of representative experiments for R4-6 and R11-15. As determined by spectroscopy at 345 and $280 \mathrm{~nm}$, vesicles alone are eluted in the $8 \mathrm{ml}$ exclusion volume of the column. Proteins alone are eluted in volumes corresponding to proteins with Stokes' radii of 3.5 and $4.1 \mathrm{~nm}$ for R4-6 and R11-15, respectively; these values fit well with monomeric forms of both proteins. When R4-6 or R11-15 are co-incubated in the presence of DOPC/DOPS vesicles prior to chromatography analysis, they are found in the exclusion volume, indicating the formation of proteinvesicle complexes. No such complexes are found when using DOPC/DOPE vesicles. Thus, we conclude that these proteins bind to PC/PS and not to PC/PE vesicles. Exclusion chromatography was also used to study the potential binding of R12-14 and R14-17 to vesicles, showing that both proteins bind to DOPC/DOPS vesicles and not to DOPC/DOPE vesicles (not shown).

In all cases, we carried out SDS-PAGE of the protein/vesicles mixtures after two hours of contact even when the complexes were separated by one or the other method. This shows that there is no degradation-proteolysis of the proteins upon binding.

These results clearly demonstrate that repeats 4 to 19 (except repeat 10, which is not included in a construct) of the dystrophin rod domain bind to DOPC/DOPS vesicles, thus inducing the formation of stable protein-lipid complexes. As the presence of anionic phospholipid PS is required, this indicates that the protein-lipid complexes are formed at least via the action of electrostatic forces. Since no negative result is obtained, we should bear in mind that, according to a previous study ${ }^{10} \mathrm{R} 1-$ 3 can also form stable lipid-protein complexes while, the R20-24 sub-domain does not bind to any type of vesicles and thus could be considered as a negative control for such experiments.

\section{Tryptophan residues are involved in protein-lipid complex formation}

Intrinsic tryptophan fluorescence is sensitive to the lipid environment, and binding to lipid vesicles induces an increase in fluorescence intensity with or without a blue shift of the emission maximum wavelength. These features have been previously reported for the first part of the dystrophin rod domain, the sub-domain R1-3. ${ }^{8 ;}$ In the present study, the tryptophan fluorescence spectra of R46, R7-9, R11-15, R12-14, R14-17 and R17-19 are modified by the presence of DOPC/DOPS vesicles, while they remain unmodified or only very slightly modified in the presence of DOPC/DOPE vesicles (Fig. 5). The fluorescence intensity is increased by $130-370 \%$, associated with a shift in fluorescence emission maximum wavelength from 1 to $5 \mathrm{~nm}$ for four of the proteins. No shift is observed in the case of R12-14, while a red shift of $1 \mathrm{~nm}$ is reported for R11-15 (Table 2). This implies that there are conformational changes of the proteins during their binding to DOPC/DOPS vesicles, while the presence of DOPC/DOPE vesicles does not greatly modify the protein conformation except that R1115 shows a significant quenching of the fluorescence intensity by about $30 \%$ in the presence of DOPC/DOPE vesicles.

These results clearly demonstrate that at least several of the tryptophan residues are placed in a modified and likely more hydrophobic environment during binding to anionic vesicles. This indicates that, in addition to electrostatic forces, hydrophobic forces are involved in the formation of proteinlipid complexes. 


\section{Alpha-helical secondary structure is not affected by protein-lipid binding}

Far UV circular dichroism spectra were acquired to monitor a possible $\alpha$-helix content modification associated with binding to DOPC/DOPS vesicles and contact with DOPC/DOPE vesicles (not shown). The molar ellipticity at $222 \mathrm{~nm}$ decreased slightly, indicating that protein binding to anionic vesicles induces a decrease of $3-12 \%$ in $\alpha$-helix content. The presence of DOPC/DOPE vesicles does not modify the spectra in any way, except for R11-15 where we note a 5\% decrease of $\alpha$ helix content. We can infer that the 2D structure of the repeats is maintained upon binding.

Since the molar ellipticity at $208 \mathrm{~nm}$ is sensitive to inter-helix association, the $\theta_{222} / \theta_{208}$ ratio has been used as a criterion of such an interaction. ${ }^{18 ; 19 ; 22}$ In Figure 3, we report the values of this ratio for proteins in the absence or presence of vesicles. In the presence of DOPC/DOPS vesicles, the $\theta_{222} / \theta_{208}$ ratio significantly decreases for the three-repeat proteins, R4-6, R7-9, R12-14 and R17-19, while it is not significantly modified for the four- and five-repeat proteins, R11-15 and R14-17. However, the $\theta_{222} / \theta_{208}$ ratio remains higher than 1 for R4-6 (which is the value expected for interacting helices in coiled-coils ${ }^{22}$ ), while it decreases to values lower than 1 for the other proteins, remaining equal to or higher than 0.90 (the values expected for non-interacting helices fall in the range 0.8-0.9). In the presence of DOPC/DOPE vesicles, the $\theta_{222} / \theta_{208}$ ratio is only lowered by a non-significant amount, with all the values remaining higher than 1 except for R7-9 where the value falls significantly to 0.92 . Therefore, we may conclude that, in the four three-repeat proteins, the inter-helix association is decreased upon binding to DOPC/DOPS vesicles, while this is not the case when they are in the presence of PC/PE vesicles. By contrast, in the two four- and five-repeat proteins, R11-15 and R1417 , the inter-helix association in coiled-coils is not apparently modified by binding to PC/PS vesicles.

In conclusion, it appears that the $2 \mathrm{D}$ structure of the proteins is unmodified by binding to anionic lipids, while the 3D structure in coiled-coils is modified in the shorter proteins but not in the longer proteins.

\section{Discussion}

The main conclusion of our study is that the rod domain of dystrophin including repeat 4 to 19 is able to bind strongly to lipid anionic vesicles, thus making up a second lipid-binding domain LBD2. The binding does not greatly modify the secondary structure of the proteins and involves electrostatic as well as hydrophobic forces.

Three repeat constructs were first expressed, and the proteins were then purified. The theoretical boundaries of each of the 24 dystrophin repeats have long been established by comparison with spectrin chains, ${ }^{23 ; 24}$ and it is clear that they are arranged in coiled-coils with a heptad pattern of the primary sequence. ${ }^{25}$ However, experimental data have shown that, in contrast to spectrin repeats, ${ }^{26}$;

27 it is impossible to express and obtain well-folded single repeats of dystrophin. ${ }^{10 ; 12 ; 13 ; 14}$ It is necessary to extend the constructs by several residues on both sides to obtain stable proteins. Such extensions are difficult to define optimally. Therefore, in our study, three-repeat proteins are produced with extensions at both $\mathrm{N}$ - and C-terminal ends by 7 to 9 residues when possible, by assuming a Winder-type alignment. ${ }^{24}$ Even with this approach, the central part of the rod domain from repeat 8 to 16 proves to be extremely difficult to produce in vitro and certain combinations of repeats remain impossible to express in high amounts or as well-folded proteins. It is noteworthy that these multirepeat proteins contain one of the three repeats lacking tryptophan residues i.e. repeats 10,11 and 14. In particular, two conserved Trp residues situated at the $17^{\text {th }}$ and $90^{\text {th }}$ places in repeats are involved in spectrin repeat stability. The absence or the mutagenesis of these residues in the spectrin repeat is accompanied by a very low stability ${ }^{28 ; 29}$ as well as a modification of the $3 \mathrm{D}$ structure ${ }^{30}$ compared to repeats containing the two Trp residues. It is likely that folding could be precluded by the presence of Trp lacking repeats in several of our constructs. However, R12-14 and R11-15 are well folded even though they contain Trp lacking repeats, so other parameters appear to be important in controlling the 
folding of these proteins. Moreover, we know that repeats 11, 13, 15 and 17 display theoretical isoelectric points higher than 7 compared to the others, which all have an isoelectric point lower than 7. These features merit further experimental investigation.

The mid-transition temperatures of the proteins analyzed here are situated between 50 and $65^{\circ} \mathrm{C}$, falling in the same range as reported in previous studies on dystrophin repeats ${ }^{14 ; 31 ; 32 ; 33}$ giving a minimum of $45^{\circ} \mathrm{C}$ and a maximum of $69^{\circ} \mathrm{C}$. The sub-domains containing repeats 1 to 3 and 20 to 24 yield $\mathrm{T}_{\mathrm{m}}$ values of 50 and $62^{\circ} \mathrm{C}$, respectively, ${ }^{10}$ while the single repeat 23 has a $\mathrm{T}_{\mathrm{m}}$ of $66^{\circ} \mathrm{C}$. It is striking that the range of mid-transition temperatures of dystrophin repeats is small compared to the erythrocyte and brain spectrin repeats. Some authors have reported stabilities of spectrin repeats ranging from $31^{\circ} \mathrm{C}$ to $63{ }^{\circ} \mathrm{C},{ }^{34}$ while others give mid-transition temperatures lower than $37^{\circ} \mathrm{C}$ and as high as $72^{\circ} \mathrm{C}^{26 ; 27}$ However, the $\mathrm{T}_{\mathrm{m}}$ of spectrin multirepeat proteins are systematically and significantly increased compared to the values for single repeats, showing that there is a cooperative stabilization of the structure. ${ }^{15 ;} 29$ In our study, the four- and five-repeat R14-17 and R11-15 proteins do not display significantly higher $\mathrm{T}_{\mathrm{m}}$ than the three repeat proteins. This agrees with our previous observations about R1-3 and R20-24 compared to single repeats R2 and R23. ${ }^{10}$ Taking into account a previous study using two-repeat constructs of dystrophin, ${ }^{33}$ it appears that our three-repeat constructs are not more stable than their two-repeat counterparts. All these results demonstrate that dystrophin repeats can be distinguished from spectrin repeats by their higher and more homogeneous stability properties compared to the large range of spectrin repeat stability.

The lipid-binding property of dystrophin rod domain was first proposed in 1997 by DeWolf in Gratzer's group ${ }^{7}$ and subsequently by our group, ${ }^{8}$ by showing that repeat 2 binds specifically to anionic phospholipids. We then started a systematic study of the entire rod domain, recently showing that the sub-domain comprising the repeats 1 to 3 binds to anionic phospholipids while the sub-domain comprising repeats 20 to 24 does not. This highlights the fact that the repeats of dystrophin have distinct properties and likely play distinct roles in the muscle cell. Here, we supplement the qualitative study and show that anionic lipids bind strongly with the sub-domain comprising repeats $4-19$. We use the same approach as used previously to unify the results in terms of lipid model. SUVs have been extensively characterized as highly curved vesicles with a high surface pressure compared to larger vesicles such as large or giant unilamellar vesicles. ${ }^{35}$ In a quantitative description of repeat 2 lipidbinding properties, we have shown that the repeat binds very weakly to LUVs compared to SUVs, except when LUVs contain PE and/or cholesterol. This evidence argues for the repeat 2 binding being influenced by lipid packing rather than curvature. ${ }^{36}$ The biochemical methods used here allow the physical separation of vesicles from free proteins. Therefore, it is clear that stable PC/PS-protein complexes are formed with significant affinity. The binding does not induce any protein hydrolysis after two hours of contact, which corroborates the formation of stable protein-lipid complexes. While we have not explicitly measured the association constants of the binding process, the ratios between protein and vesicle phospholipids are similar to the ratios previously used ${ }^{8 ; 36}$ and lead to a binding of more than $90 \%$ of the proteins.

Tryptophan fluorescence has long been used to study the conformation of proteins and monitor changes of the tryptophan environment associated with binding to a number of ligands including lipids. The intrinsic tryptophan fluorescence is quenched in folded proteins by several mechanisms, including excited-state electron transfer from the indole ring to amino-acid side chains, in particular glutamine, asparagine, glutamic and aspartic acids, as well as cysteine and histidine ${ }^{37}$. Electron transfer also occurs towards the peptide bond. ${ }^{38}$ The proximity and geometry of the indole ring in relation to the surrounding side chains can suppress or enhance tryptophan quenching, and therefore modify fluorescence quantum yield (and hence intensity) as well as maximum emission wavelength. However, tryptophan has a preference for membrane interfaces, ${ }^{39 ; 40}$ where the indole ring can accommodate with the phospholipid glycerol backbone. Under such conditions of lipid proximity and folding modification, the fluorescence emission shows an increase in quantum yield and intensity, as well as a shift of maximum wavelength towards the blue end of the spectrum. The fluorescence intensity of the studied proteins is largely modified in the presence of anionic phospholipid vesicles, while the maximum emission wavelength is slightly shifted to the blue end in four of these proteins, as previously observed with repeat $2^{8}$ and sub-domain $\mathrm{R} 1-3 .{ }^{10}$ The two longest proteins show no blue 
shift or a small red shift of the maximum emission wavelength, possibly due to large environmental changes that could enhance or decrease quenching of the numerous tryptophan residues via the surrounding side chains. Overall, these results indicate that at least one or several tryptophan residues in proteins are less quenched. In this way, they are concomitantly placed into a more hydrophobic environment as expected during lipid binding. Indeed, there is more than one tryptophan residue per protein, and we cannot assign a lipid-binding property to any one of them specifically. Moreover, far UV circular dichroism at $222 \mathrm{~nm}$ shows only a slight decrease of the protein $\alpha$-helix content, indicating that the overall secondary structure of the repeats is maintained in the protein-lipid complexes. However, even though the 2D structure in $\alpha$-helix is not modified, the molar ellipticity at $208 \mathrm{~nm}$ - and therefore the $\theta_{222} / \theta_{208}$ ratio as well - are significantly decreased upon lipid-binding of the four three-repeat proteins. This decrease in values upon lipid-binding indicates a lower degree of interhelix interaction, ${ }^{18 ;} 22$ leading to the idea that coiled-coils open when binding to lipids. However, the ratio does not reach the values of 0.8-0.9 observed in proteins in the presence of TFE, when there is complete disruption of the inter-helix association. ${ }^{20 ; 21}$ Therefore, it appears that the coiled-coils only open partly upon lipid binding. This implies that only some of the nine helices present in the threerepeat proteins no longer interact to form coiled-coils. The fact that the large proteins, R11-15 and R14-17 fail to show any apparent modification of the $\theta_{222} / \theta_{208}$ ratio may suggest they are not modified upon binding to anionic lipids. However, there are insufficient examples of the use of CD at 208 and $222 \mathrm{~nm}$ of proteins upon lipid binding in solution, so we cannot infer the absence of transconformation of these proteins. With such large proteins, it may be more complex to carry out the analysis of CD spectra. Other factors may contribute to the overall values of CD at 208 and $222 \mathrm{~nm}$, hence precluding the use of the ratio to monitor inter-helical interactions in such large proteins.

Hence, we tentatively conclude that binding of the proteins to anionic lipids initially occurs via an electrostatic force which, in turn, induces a trans-conformation; this trans-conformation results in a partial opening of the 3D coiled-coil structure, which allows the transfer of some of the Trp into a more hydrophobic environment. At present, we have no grasp of the molecular/structural mechanism by which the helices could "open" during lipid-binding. There is currently no available structural data on any dystrophin repeat. We performed molecular modelling of the wild type and mutated repeat 23, showing that the coiled-coil is a very good model for this repeat. ${ }^{41}$

No protein-lipid complexes could be detected by biochemical methods following contact of the proteins with $\mathrm{PC} / \mathrm{PE}$ vesicles; however, the fluorescence spectrum of R11-15 is systematically quenched by about $30 \%$ in the presence of such vesicles, which represents a notably large modification. This could be interpreted as due to a weak interaction with PC/PE, which precludes the formation of sufficiently stable protein-lipid complexes to be recovered during exclusion chromatography. It is noteworthy that R11-15 has actin-binding properties ${ }^{6}$ in addition to the lipidbinding properties shown here. Therefore, it is tempting to consider that this protein has specific biochemical properties. This point deserves to be investigated by further experiments.

Numerous studies have been carried out on the lipid-binding properties of spectrin repeats, giving rise to an extensive review by Sikorski et al.. ${ }^{42}$ The binding properties of PS as well as PE vesicles with spectrin repeats are reported in the literature, in contrast to our studies where we failed to demonstrate any significant PE binding of dystrophin repeats, except for a weak binding of R11-15 to $\mathrm{PC} / \mathrm{PE}$ observed by fluorescence spectroscopy. Considering the lipid-binding properties of dystrophin repeats, this is a first significant difference between the two proteins of the same family. Moreover, in erythrocyte and brain $\alpha$-and $\beta$-spectrin, anionic-lipid binding repeats are concentrated in clusters of two/three repeats. ${ }^{11 ; 43}$ By contrast, we find evidence for one cluster of non-lipid-binding repeats, i.e. repeat 20-24, as shown in an earlier study. ${ }^{10}$ This is a second significant difference between the lipidbinding properties of dystrophin compared to spectrin. However, since we did not produce single repeats, we cannot rule out the hypothesis of one or several repeats which do not bind to phospholipids as such but are included in larger regions binding to lipids. Considering that R4-6 and R7-9 have no overlapping regions, a yet unknown part of each of these proteins may interact with lipids. R11-15, R12-14 and R14-17 have the repeat 14 in common; however, since this repeat does not contain any tryptophan residue, fluorescence can only be due to one or several of the other repeats. While repeat 11 does not contain any tryptophan residue, such interactions might concern repeats 12,13 and 17. 
Therefore, it seems that an unknown part of these repeats is able to interact with lipids in the region from repeat 11 to 15 . For the region R14-17, the repeat 17 is common with R17-19, so we cannot rule out the possibility that only repeat 17 can bind to lipids. However, we should note that, even in single spectrin repeats, there is so far no experimental evidence of specific residues interacting with lipids. The specific lipid-binding sites are able to position the multi-repeat proteins very near the vesicles, thus allowing the formation of stable lipid-protein complexes.

Even though there are broad similarities between the primary sequences of spectrin and dystrophin, as well as in the overall arrangement of the molecules, there are significant differences that could be assigned to different biological functions of the two molecules. As a whole, dystrophin repeats are more stable than the spectrin repeats. It is noteworthy that the lipid-binding spectrin repeats are among the least stable. Erythrocyte and brain spectrin repeats with lipid-binding properties display $\mathrm{T}_{\mathrm{m}}$ below $50^{\circ} \mathrm{C}^{26}$ and $40{ }^{\circ} \mathrm{C},{ }^{27}$ respectively. This is not the case for dystrophin repeats, where the rod domain repeats 1 to 19 bind to phospholipids and display $\mathrm{T}_{\mathrm{m}}$ values distributed over the small range of 50 to $65^{\circ} \mathrm{C}$. The most important difference between spectrin and dystrophin is that spectrin chains make up $\alpha / \beta$ dimers which in turn form a tetramer. Such a process has never been shown for the dystrophin molecule. It is likely that the dimerization property of spectrin could be involved in such differences.

Taking into account all these results, we propose to assign two lipid-binding domains for dystrophin (Fig.6A). The lipid-binding domain 1 (LBD1) comprises the well defined region R1-3 as reported previously ${ }^{10}$ while the lipid-binding domain 2 (LBD2) comprises the central rod domain R4-19 as shown here. The region R11-15 makes up the $2^{\text {nd }}$ actin-binding domain of dystrophin ${ }^{6 ; 44}$ and we show here that it also binds to membrane phospholipids. It remains to be elucidated whether these two binding properties play a simultaneous role or are competitive. However, by these interactions, it is evident that the dystrophin molecule is situated very near the sarcolemma, with a large part of the rod domain lying along the lipid bilayer as illustrated in Fig. 6B. The biological relevance of such domain studies is a fundamental question. The lipid-binding properties of intact dystrophin have so far not been investigated, essentially because dystrophin is a heavy protein that can be more readily studied in terms of specific domains rather than as a whole. However, since dystrophin is a filamentous protein with more than $75 \%$ of its structure made up of a linear chain of repeats, we can assume that the series of several repeats studied here are representative of the whole molecule.

When dystrophin is absent from muscle, the sarcolemma is very frequently disrupted $45 ; 46 ; 47$ and a higher susceptibility to eccentric contractions is observed ${ }^{48 ; 49 ; 50}$ leading to a high number of leaky muscle fibres. Accordingly, immobilization of dystrophin-deficient muscle is accompanied by markedly reduced signs of dystrophy. ${ }^{51 ; 52 ; 53}$ These observations clearly indicate that dystrophin is involved in the mechanical resistance against the stress induced by the contraction-relaxation cycles of active muscle. Through interactions with cytoskeletal actin, the dystrophin-glycoprotein complex proteins and membrane phospholipids, dystrophin acts as a physical link between cytoskeleton and extracellular matrix which could behave as a "shock absorber" dampening elastic extension during muscle stretching. ${ }^{54 ; 55}$ This role could involve interaction of the dystrophin molecule with the cytoskeletal $\gamma$-actin. A second molecular aspect of this mechanical function could be related to the intrinsic properties of the lipid bilayer. The cohesion of the cellular lipid bilayer is ensured by its association with cytoskeleton proteins, which provide it with a "solid support". 56; 57 Thus, by interacting with phospholipids, specialized cytoskeleton proteins are able to maintain the cohesion of the lipid molecules during compression and re-extension of the membrane. Such proteins are associated, for example, with pulmonary surfactant, ${ }^{58}$ and spectrin plays such a role in red blood cells. ${ }^{9 ; 59}$ In muscle cells, this role as a "solid support" could be played by dystrophin molecule by its interaction with the lipid bilayer.

Our results show that the major part of the dystrophin rod domain binds to membrane lipids, which offers new avenues for investigating the comprehensive role of dystrophin in the muscle cell and a new basis for understanding the molecular genesis of the pathology induced by dystrophin deficiency.

\section{Materials and Methods}




\section{Reagents}

All lipids were obtained from Avanti Polar Lipids (Alabama, US), and were used without further purification. The pGEX-4T1 plasmid vector, GST-Trap ${ }^{\mathrm{TM}}$ HP column and HiTrap ${ }^{\mathrm{TM}}$ columns were purchased from GE Healthcare, while restriction enzymes were supplied by Ozyme (St Quentin-enYvelines, France) and Promega (Charbonnières, France). The IMPACT ${ }^{\mathrm{TM}}$ kit (Intein Mediated Purification with an Affinity Chitin-binding Tag), including the pTYB1 vector, chitin beads and E. coli host strain ER2566, was purchased from Ozyme.

\section{Cloning}

The plasmid pTG11025 harbouring the cDNA for the Dp427m muscle isoform of human dystrophin (NCBI Nucleotide Data base NM-004006, provided by S. Braun Transgene, France) was used as a template for PCR amplification of fragments encoding three-repeat proteins (R4-6 to R17-19) and one four-repeat protein (R14-17) of the dystrophin rod domain, as shown in Fig. 1A. Small extensions of 7-9 amino acid residues were added at both $\mathrm{N}$ - and C-termini of multi-repeat proteins to improve stability of the coiled-coil motifs (Table 1), as recommended previously, ${ }^{12}$ except for the repeats adjacent to hinges (R4 and R19). R14-16 and R14-17 were extended by two residues only at the $\mathrm{N}$-terminus to avoid the presence of a helix-breaker proline residue at the beginning of the protein sequence. Table 1 gives the exact boundaries of the multi-repeat proteins. To avoid further small aminoacid extensions of the recombinant proteins arising from cleavage of the fusion proteins, PCR were amplified with 5' primers containing the Nde I restriction site and 3' primers with half parts corresponding to the eighteen first bases of the intein sequence of the pTYB1 vector from TGCTTT up to the Kpn I restriction site. In this way, cloning of such PCR products into pTYB1 using the Nde I and Kpn I restriction sites allowed suppression of the MCS and expression of the dystrophin rod fragments directly fused with the full intein tag at the C-terminus.

The cDNA encoding R11-15, similar to the actin-binding domain situated in the rod domain, ${ }^{6}$ was cloned into pGEX-4T1 downstream of the sequence of Glutathione S-transferase (GST) using Bam $\mathrm{HI}$ and Xho I restriction sites. The boundaries of R11-15 were chosen without any extension based on the alignment of spectrin triple helical repeats of dystrophin. ${ }^{24}$

All the PCR amplified products were checked by a Big Dye terminator sequencing procedure.

\section{Protein expression and purification}

Proteins were expressed in the protease-deficient Escherichia coli ER2566 strain as proteins tagged by GST or intein-chitin binding domain (Intein-CBD), and then purified by affinity chromatography followed by ion-exchange chromatography. Cultures were grown to an absorbance at $600 \mathrm{~nm}$ of $0.6-0.8$ at $37^{\circ} \mathrm{C}$ in LB supplemented with $100 \mu \mathrm{g} \cdot \mathrm{mL}^{-1}$ ampicillin, and then induced to express intein-CDB fusion proteins with $0.5 \mathrm{mM}$ isopropyl- $\beta$-D-thiogalactopyranoside (IPTG) at $25^{\circ} \mathrm{C}$ overnight or GST-R11-15 protein with $1 \mathrm{mM}$ IPTG for 4 hours at $37^{\circ} \mathrm{C}$. After harvesting, bacterial pellets were resuspended in ice-cold column buffer ( $20 \mathrm{mM}$ Tris- $\mathrm{HCl}, 150 \mathrm{mM} \mathrm{NaCl}, \mathrm{pH} 7.5)$, subjected to sonication on ice ten times for $30 \mathrm{~s}$ and then clarified by centrifugation at $13,000 \mathrm{~g}$.

GST-R11-15 protein was purified on a GST-Trap ${ }^{\mathrm{TM}} \mathrm{HP}$ column and released after enzymatic cleavage with thrombin as previously described for R1-3. ${ }^{10}$ Intein-CBD tagged proteins were loaded onto a pre-equilibrated chitin column $(5 \mathrm{~mL})$ at $0.5 \mathrm{~mL} \cdot \mathrm{min}^{-1}$. After washing with column buffer, the column was quickly flushed with cleavage buffer $(20 \mathrm{mM}$ Tris- $\mathrm{HCl}, 150 \mathrm{mM} \mathrm{NaCl}$, DTT $50 \mathrm{mM} \mathrm{pH}$ 7.5), and then on-column cleavage took place for 48 hours at $4^{\circ} \mathrm{C}$. Elution was performed in the column buffer. In cases where proteins needed further purification, ion exchange chromatography was performed on $1 \mathrm{~mL}$ HiTrap ${ }^{\mathrm{TM}} \mathrm{Q}$ column with a $\mathrm{NaCl}$ gradient in Tris $20 \mathrm{mM} \mathrm{pH} 7.5$, except for R12-14 which required HiTrap ${ }^{\mathrm{TM}}$ SP. Purified proteins were dialysed extensively against TNE buffer $(20 \mathrm{mM}$ Tris- $\mathrm{HCl}, 150 \mathrm{mM} \mathrm{NaCl}, 0.1 \mathrm{mM}$ EDTA, $\mathrm{pH}$ 7.5), concentrated and quantified using the BCA (bicinchoninic acid) protein assay. 


\section{Phospholipid vesicle preparations}

Multilamellar vesicles were first prepared. Mixtures containing two parts of DOPC and one part DOPS or DOPE in chloroform were dried overnight under vacuum and suspended in TNE buffer. Small unilamellar vesicles (SUV) were prepared from MLV diluted at $25 \mathrm{mg} \cdot \mathrm{mL}^{-1}$ and sonicated at room temperature with the micro-tip of a sonicator for $1 \mathrm{~min}$ with half-duty cycles. The SUVs were then centrifuged at $20000 \mathrm{~g}$ to eliminate titanium impurities. The SUV sizes determined by dynamic light scattering (4700/PCS100 Malvern) were about 50-60 nm for DOPC/DOPS and DOPC/DOPE lipid mixtures. Oxidation products were not detected in the SUVs obtained by sonication. ${ }^{36}$

\section{Separation of protein-lipid complexes from free protein}

To separate free protein from vesicles with or without bound protein, gel-filtration chromatography or velocity sedimentation on sucrose density gradient were performed with dystrophin sub-domains or vesicles alone and with vesicles/protein mixtures. Gel-filtration chromatography was performed on a Sephacryl S-200 column $(10 \times 300 \mathrm{~mm})$. The column was loaded with $100-\mu \mathrm{L}$ samples of i) proteins alone at $5 \mu \mathrm{M}$, ii) DOPC/DOPS or DOPC/DOPE SUVs alone $(5 \mathrm{mM})$ or iii) protein/SUVs mixtures $(1 / 1000, \mathrm{M} / \mathrm{M})$. The column was eluted at $10^{\circ} \mathrm{C}$ with TNE buffer at a flow rate of $0.5 \mathrm{~mL} \cdot \mathrm{min}^{-1}$ and fractions of $1 \mathrm{~mL}$ were collected. The standard proteins used for column calibration were alcohol deshydrogenase $(\mathrm{Rs}=4.6 \mathrm{~nm})$, bovine serum albumin $(\mathrm{Rs}=3.5 \mathrm{~nm})$, ovalbumin $(\mathrm{Rs}=2.7 \mathrm{~nm})$ and cytochrome $\mathrm{c}(\mathrm{Rs}=1.7 \mathrm{~nm})$. Elution was monitored by recording the absorbance at $280 \mathrm{~nm}$ for proteins and at $345 \mathrm{~nm}$ for vesicles. The fractions corresponding to the exclusion volume of the column and the elution volumes of single proteins were analysed by SDS-PAGE followed by silver staining.

For velocity sedimentation, we used $5 \mathrm{~mL}$ linear $2-20 \%(\mathrm{w} / \mathrm{v})$ sucrose density gradients prepared from sucrose stock solutions in TNE buffer. $100 \mu \mathrm{L}$ of proteins, vesicles or vesicle-protein mixtures were layered on top of the gradient and ultracentrifugation was performed at $100,000 \mathrm{~g}$ for $16 \mathrm{~h}$ at $4^{\circ} \mathrm{C}$. Calibration curves for the determination of the apparent sedimentation coefficient were constructed using cytochrome $C\left(\mathrm{~S}_{20, \mathrm{w}}=1.7 \mathrm{~S}\right)$, bovine serum albumin $\left(\mathrm{S}_{20, \mathrm{w}}=4.3 \mathrm{~S}\right)$ and $\operatorname{IgG}\left(\mathrm{S}_{20, \mathrm{w}}=7 \mathrm{~S}\right)$. Following centrifugation, 21 fractions were collected from the bottom of each gradient. Absorbance at $345 \mathrm{~nm}$ was used for detection of vesicles. SDS-PAGE followed by Coomassie Blue staining was used for protein detection.

\section{Far UV circular dichroism spectropolarimetry}

Far UV circular dichroism spectra were recorded on a Jasco J-815 spectropolarimeter (JobinYvon, Nantes, France) under $\mathrm{N}_{2}$ atmosphere at $20^{\circ} \mathrm{C}$ using a path length of $0.2 \mathrm{~cm}$ in a quartz cell with two-three accumulations. Blanks corresponding to buffer or SUVs alone were subtracted from the spectra. The molar ellipticity at $222 \mathrm{~nm}$ was calculated using the mean residue molar concentration of the proteins and the percentage of $\alpha$-helix was obtained using a $100 \% \alpha$-helix value of -36000 deg. $\mathrm{cm}^{2} . \mathrm{dmol}^{-1}$ at $222 \mathrm{~nm} .{ }^{60}$ The heat-induced unfolding was monitored by $\mathrm{CD}$ at $222 \mathrm{~nm}$ with protein concentrations of about $2.5 \mu \mathrm{M}$ in TNE buffer, increasing temperature in increments of $1 \mathrm{deg} / \mathrm{min}$ from 15 to $85^{\circ} \mathrm{C}$ using a Peltier device, with temperature equilibration steps of $30 \mathrm{~s}$. To determine to what extent thermal unfolding is reversible upon cooling, a second set of data was obtained for each protein by heating to about 7 degrees above the melting temperature observed in the first set of data, i.e. from 15 to $85^{\circ} \mathrm{C}$. The temperature was allowed to return to $15^{\circ} \mathrm{C}$ very rapidly after reaching the last temperature point and the spectrum was acquired at $20^{\circ} \mathrm{C}$ after 30 min of cooling.

Circular dichroism signals at $222 \mathrm{~nm}$ subtracted from background were fitted to the following equation describing unfolding as a two-state thermodynamic process according to Becktel ${ }^{61}$ and as used previously for dystrophin repeat unfolding ${ }^{10}$ : (equation 1)

$$
\left.\mathrm{y}=\left[\left(\alpha_{\mathrm{N}}+\beta_{\mathrm{N}} \mathrm{T}+\left(\alpha_{\mathrm{D}}+\beta_{\mathrm{D}} \mathrm{T}\right) \exp \left(-\Delta \mathrm{H}^{0}{ }_{\text {un }}+\mathrm{T} \Delta \mathrm{S}^{0}{ }_{\text {un }}\right) / \mathrm{RT}\right)\right] /\left[1+\exp \left(-\Delta \mathrm{H}^{0}{ }_{\text {un }}+\mathrm{T} \Delta \mathrm{S}_{\text {un }}^{0}\right) / \mathrm{RT}\right)\right]
$$

where $y$ is the value at temperature $T, \alpha_{N}$ and $\alpha_{D}$ are the intercepts of the native and denatured states, respectively, $\beta_{\mathrm{N}}$ and $\beta_{\mathrm{D}}$ are the slopes of the native and denatured states, respectively, $\Delta \mathrm{H}^{0}$ un and $\Delta \mathrm{S}_{\text {un }}^{0}$ are the entropy and enthalpy changes for unfolding, respectively, and $\mathrm{R}$ is the gas constant in $\mathrm{J} \mathrm{mol}^{-1} \mathrm{~K}^{-1}$. 


\section{Fluorescence spectroscopy}

Tryptophan intrinsic fluorescence spectra were recorded on a Fluorolog 3 spectrofluorometer (Jobin-Yvon, Longjumeau, France) at $20^{\circ} \mathrm{C}$ in a correct mode between $310 \mathrm{~nm}$ and $420 \mathrm{~nm}$ (bandwidth, $5 \mathrm{~nm}$ ) with an excitation wavelength of $295 \mathrm{~nm}$ (bandwidth, $1 \mathrm{~nm}$ ) in $300 \mu \mathrm{L}$ using $10 \times 10-\mathrm{mm}$ quartz cells. Blanks were subtracted using the same experimental conditions (i.e. buffer, SUVs). Fluorescence intensities were obtained by integrating the spectra in the range $310-420 \mathrm{~nm}$.

\section{Acknowledgments}

This work was supported in part by the "Association Française contre les Myopathies" (AFM). SL was a recipient of a grant from the "Conseil Régional de Bretagne" (PRIR 1351). The authors wish to thank S. Pastezeur and S. Dréano for DNA sequencing. M.S.N. Carpenter post-edited the English style.

\section{References}

1. Koenig, M., Hoffman, E. P., Bertelson, C. J., Monaco, A. P., Feener, C. \& Kunkel, L. M. (1987). Complete cloning of the Duchenne muscular dystrophy (DMD) cDNA and preliminary genomic organization of the DMD gene in normal and affected individuals. Cell 50, 509-17.

2. Deconinck, N. \& Dan, B. (2007). Pathophysiology of duchenne muscular dystrophy: current hypotheses. Pediatr Neurol 36, 1-7.

3. Ervasti, J. \& Campbell, K. (1991). Membrane organization of the dystrophin-glycoprotein complex. Cell 66, 1121-1131.

4. Campbell, K. \& Kahl, S. (1989). Association of dystrophin and an integral membrane glycoprotein. Nature 338, 259-262.

5. Rybakova, I., Amann, K. \& Ervasti, J. (1996). A new model for the interaction of dystrophin with F-actin. J Cell Biol 135, 661-672.

6. Amann, K. J., Renley, B. A. \& Ervasti, J. M. (1998). A Cluster of Basic Repeats in the Dystrophin Rod Domain Binds F-actin through an Electrostatic Interaction. J Biol Chem 273, 28419-28423.

7. DeWolf, C., McCauley, P., Sikorski, A. F., Winlove, C. P., Bailey, A. I., Kahana, E., Pinder, J. C. \& Gratzer, W. B. (1997). Interaction of dystrophin fragments with model membranes. Biophys J 72, 2599-2604.

8. Le Rumeur, E., Fichou, Y., Pottier, S., Gaboriau, F., Rondeau-Mouro, C., Vincent, M., Gallay, J. \& Bondon, A. (2003). Interaction of dystrophin rod domain with membrane phospholipids: evidence of a close proximity between tryptophan residues and lipids. J Biol Chem 278, 59936001 .

9. Manno, S., Takakuwa, Y. \& Mohandas, N. (2002). Identification of a functional role for lipid asymmetry in biological membranes: phosphatidylserine - skeletal protein interactions modulate membrane stability. Proc Natl Acad Sci (USA) 99, 1943-1948.

10. Legardinier, S., Hubert, J.-F., Le Bihan, O., Tascon, C., Rocher, C., Raguénès-Nicol, C., Bondon, A., Hardy, S. \& Le Rumeur, E. (2008). Sub-domains of the dystrophin rod domain display contrasting lipid-binding and stability properties. Biochim Biophys Acta, 1784, 672-682.

11. An, X., Guo, X., Sum, h., Morrow, J., Gratzer, W. \& Mohandas, N. (2004). Phosphatidylserine binding sites in erythroid spectrin: location and implications for membrane stability.

Biochemistry 43, 310-315.

12. Kahana, E. \& Gratzer, W. B. (1995). Minimum folding unit of dystrophin rod domain. Biochemistry 34, 8110-4.

13. Kahana, E., Marsh, P. J., Henry, A. J., Way, M. \& Gratzer, W. B. (1994). Conformation and phasing of dystrophin structural repeats. JMol Biol 235, 1271-7. 
14. Saadat, L., Pittman, L. \& Menhart, N. (2006). Structural cooperativity in spectrin type repeats motifs of dystrophin. Biochim Biophys Acta 1764, 943-954.

15. MacDonald, R. \& Pozharski, E. (2001). Free energies of urea and thermal unfolding show that two tandem repeats of spectrin are thermodynamically more stable than a single repeat.

Biochemistry 40, 3974-3984.

16. Batey, S. \& Clarke, J. (2006). Apparent cooperativity in the folding of multidomain proteins depends on the relative rates of folding of the constituent domains. Proc Natl Acad Sci (USA) 103, 18113-8.

17. Long, F., McElheny, D., Jiang, S., Park, S., Caffrey, M. S. \& Fung, L. W. (2007).

Conformational change of erythroid alpha-spectrin at the tetramerization site upon binding betaspectrin. Protein Sci 16, 2519-30.

18. Lau, S. Y., Taneja, A. K. \& Hodges, R. S. (1984). Synthesis of a model protein of defined secondary and quaternary structure. Effect of chain length on the stabilization and formation of two-stranded alpha-helical coiled-coils. J Biol Chem 259, 13253-61.

19. Mehboob, S., Luo, B. H., Patel, B. M. \& Fung, L. W. (2001). alpha beta Spectrin coiled coil association at the tetramerization site. Biochemistry 40, 12457-64.

20. Paulucci, A. A., Hicks, L., Machado, A., Miranda, M. T., Kay, C. M. \& Farah, C. S. (2002). Specific sequences determine the stability and cooperativity of folding of the C-terminal half of tropomyosin. J Biol Chem 277, 39574-84.

21. Choy, N., Raussens, V. \& Narayanaswami, V. (2003). Inter-molecular coiled-coil formation in human apolipoprotein E C-terminal domain. J Mol Biol 334, 527-39.

22. Zhou, N. E., Kay, C. M. \& Hodges, R. S. (1992). Synthetic model proteins. Positional effects of interchain hydrophobic interactions on stability of two-stranded alpha-helical coiled-coils. $J$ Biol Chem 267, 2664-70.

23. Koenig, M. \& Kunkel, L. M. (1990). Detailed analysis of the repeat domain of dystrophin reveals four potential hinge segments that may confer flexibility. J Biol Chem 265, 4560-4566.

24. Winder, S., Gibson, T. \& Kendrick-Jones, J. (1995). Dystrophin and utrophin: the missing links! FEBS Letters 369, 27-33.

25. Lupas, A. (1996). Coiled coils: new structures and new functions. Trends Biochem Sci 21, 37582.

26. An, X., Guo, X., Zhang, X., Baines, A. J., Debnath, G., Moyo, D., Salomao, M., Bhasin, N., Johnson, C., Discher, D., Gratzer, W. B. \& Mohandas, N. (2006). Conformational stabilities of the structural repeats of erythroid spectrin and their functional implications. J Biol Chem 281, 10527-32.

27. An, X., Zhang, X., Salomao, M., Guo, X., Yang, Y., Wu, Y., Gratzer, W., Baines, A. J. \& Mohandas, N. (2006). Thermal stabilities of brain spectrin and the constituent repeats of subunits. Biochemistry 45, 13670-6.

28. Pantazatos, D. P. \& MacDonald, R. I. (1997). Site-directed mutagenesis of either the highly conserved Trp-22 or the moderately conserved Trp-95 to a large, hydrophobic residue reduces the thermodynamic stability of a spectrin repeating unit. J Biol Chem 272, 21052-9.

29. MacDonald, R. \& Cumming, J. (2004). Stabilities of folding of clustered, two-repeat fragments of spectrin reveal a potential hinge in the human erythroid spectrin tetramer. Proc. Natl. Acad. Sci (USA) 101, 1502-1507.

30. Kusunoki, H., MacDonald, R. \& Mondragon, A. (2004). Structural insights onto the stability and flexibility of unusual erythroid spectrin repeats. Structure 12, 645-656.

31. Calvert, R., Kahana, E. \& Gratzer, W. B. (1996). Stability of the dystrophin rod domain fold: evidence for nested repeating units. Biophys J 71, 1605-10.

32. Kahana, E., Flood, G. \& Gratzer, W. B. (1997). Physical properties of dystrophin rod domain. Cell Motil Cytoskeleton 36, 246-52.

33. Mirza, A. \& Menhart, N. (2008). Stability of dystrophin STR fragments in relation to junction helicity. Biochim Biophys Acta 1784, 1301-9.

34. Kusunoki, H., Minasov, G., MacDonald, R. \& Mondragon, A. (2004). Independent movement, dimerization and stability of tandem repeats of chicken brain alpha-spectrin. J Mol Biol 344, 495-511.

35. Traikia, M., Warschawski, D., Lambert, O., Rigaud, J. \& Devaux, P. (2002). Asymmetrical Membranes and Surface Tension. Biophys J 83, 1443-1454. 
36. Le Rumeur, E., Pottier, S., Da Costa, G., Metzinger, L., Mouret, L., Rocher, C., Fourage, M., Rondeau-Mouro, C. \& Bondon, A. (2007). Binding of the dystrophin second repeat to membrane di-oleyl phospholipids is dependent upon lipid packing. Biochim Biophys Acta 1768, 648-54.

37. Chen, Y. \& Barkley, M. D. (1998). Toward understanding tryptophan fluorescence in proteins. Biochemistry 37, 9976-82.

38. Pan, C. P. \& Barkley, M. D. (2004). Conformational effects on tryptophan fluorescence in cyclic hexapeptides. Biophys $J$ 86, 3828-35.

39. Yau, W.-M., Wimley, W. C., Gawrisch, K. \& White, S. H. (1998). The preference of tryptophan for membrane interfaces. Biochemistry 37, 14713-14718.

40. Clayton, A. H. \& Sawyer, W. H. (1999). Tryptophan rotamer distributions in amphipathic peptides at a lipid surface. Biophys $J 76,3235-42$.

41. Legardinier, S., Legrand, B., Raguénès-Nicol, C., Bondon, A., Hardy, S., Tascon, C., Le Rumeur, E. \& Hubert, J. F. (2009). A two amino-acid mutation encountered in Duchenne muscular dystrophy decreases stability of the R23 spectrin-like repeat of dystrophin. $J$ Biol Chem 284, 8822-8832.

42. Grzybek, M., Chorzalska, A., Bok, E., Hryniewicz-Jankowska, A., Czogalla, A., Diakowski, W. \& Sikorski, A. F. (2006). Spectrin-phospholipid interactions Existence of multiple kinds of binding sites? Chem Phys Lipids 141, 133-141.

43. An, X., Guo, X., Gratzer, W. \& Mohandas, N. (2005). Phospholipid binding by proteins of the spectrin family: a comparative study. Biochem Biophys Res Commun 327, 794-800.

44. Sonnemann, K. J., Fitzsimons, D. P., Patel, J. R., Liu, Y., Schneider, M. F., Moss, R. L. \& Ervasti, J. M. (2006). Cytoplasmic gamma-actin is not required for skeletal muscle development but its absence leads to a progressive myopathy. Dev Cell 11,387-97.

45. Mokri, B. \& Engel, A. G. (1975). Duchenne dystrophy: electron microscopic findings pointing to a basic or early abnormality in the plasma membrane of the muscle fiber. Neurology 25, 1111-20.

46. Menke, A. \& Jockusch, H. (1995). Extent of shock-induced membrane leakage in human and mouse myotubes depends on dystrophin. J Cell Sci 108, 727-733.

47. Straub, V., Rafael, J. A., Chamberlain, J. S. \& Campbell, K. P. (1997). Animal models for muscular dystrophy show different patterns of sarcolemmal disruption. J Cell Biol 139, 375-85.

48. Hutter, O., Burton, F. \& Bovell, D. (1991). Mechanical properties of normal and mdx mouse sarcolemma: bearing on function of dystrophin. J Muscle Res Cell Motil 12, 585-589.

49. Petrof, B. J., Shrager, J. B., Stedmann, H. H., Kelly, A. M. \& Sweeney, H. L. (1993). Dystrophin protects the sarcolemma from stresses developed during muscle contraction. Proc Natl Acad Sci (USA) 90, 3710-3714.

50. Nguyen, F., Cherel, Y., Guigand, L., Goubault-Leroux, I. \& Wyers, M. (2002). Muscle lesions associated with dystrophin deficiency in neonatal golden retriever puppies. J Comp Path 126, 100-108.

51. Mizuno, Y. (1992). Prevention of myonecrosis in mdx mice: effect of immobilization by the local tetanus method. Brain Dev 14, 319-22.

52. Mokhtarian, A., Lefaucheur, J. P., Even, P. C. \& Sebille, A. (1999). Hindlimb immobilization applied to 21-day-old mdx mice prevents the occurrence of muscle degeneration. J Appl Physiol 86, 924-31.

53. Etard, C., Behra, M., Ertzer, R., Fischer, N., Jesuthasan, S., Blader, P., Geisler, R. \& Strahle, U. (2005). Mutation in the delta-subunit of the nAChR suppresses the muscle defects caused by lack of Dystrophin. Dev Dyn 234, 1016-25.

54. Ervasti, J. M. (2003). Costameres: the Achilles' heel of Herculean muscle. J Biol Chem 278, 13591-4.

55. Ervasti, J. M. (2007). Dystrophin, its interactions with other proteins, and implications for muscular dystrophy. Biochim Biophys Acta 1772, 108-17.

56. Hamill, O. \& Martinac, B. (2001). Molecular basis of mechanotransduction in living cells. Physiol Rev 81, 685-740.

57. Sheetz, M. P., Sable, J. E. \& Dobereiner, H. G. (2006). Continuous membrane-cytoskeleton adhesion requires continuous accommodation to lipid and cytoskeleton dynamics. Annu Rev Biophys Biomol Struct 35, 417-34. 
58. Serrano, A. G. \& Perez-Gil, J. (2006). Protein-lipid interactions and surface activity in the pulmonary surfactant system. Chem Phys Lipids 141, 105-18.

59. Sens, P. \& Gov, N. (2007). Force balance and membrane shedding at the red-blood-cell surface. Phys Rev Lett 98, 018102.

60. Greenfield, N. \& Fasman, G. D. (1969). Computed circular dichroism spectra for the evaluation of protein conformation. Biochemistry 8, 4108-4116.

61. Becktel, W. J. \& Schellman, J. A. (1987). Protein stability curves. Biopolymers 26, 1859-77. 


\section{Legends to Figures}

Fig.1. Schematic representation of the dystrophin domains. The entire dystrophin molecule with: NT, N-terminal domain; C, Cys-rich domain; CT, C-terminal domain; H1 to H4, hinges 1 to 4. White boxes represent the 24 repeats of the rod domain. The different multirepeat constructs corresponding to the centre of the rod domain are shown.

Fig.2. Heat-induced unfolding measured by circular dichroism. Heat-induced unfolding determined by $\mathrm{CD}$ at $222 \mathrm{~nm}$ with temperature increase from 15 to $85^{\circ} \mathrm{C}$. Proteins concentrations are $5 \mu \mathrm{M}$ in TNE buffer at $\mathrm{pH}$ 7.5. For each experimental data expressed as \% of unfolding (open circles), a solid curve represents the best fit related to Eq. 1 describing the temperature-unfolding as a two-state process. $\mathrm{T}_{\mathrm{m}}$ is calculated as $\Delta \mathrm{H}^{0}{ }_{\text {un }} / \Delta \mathrm{S}_{\text {un }}^{0}$ and is indicated on each curve. Insets show the CD spectra of the protein before heating (solid lines) and after heating to 7 degrees above the $T_{m}$ first determined (dashed lines). The percentage of $\alpha$-helix content obtained from CD at $222 \mathrm{~nm}$ before heating is indicated on each inset.

Fig.3. Far UV circular dichroism $\boldsymbol{\theta}_{222} / \boldsymbol{\theta}_{208}$ ratio of proteins with or without presence of lipid vesicles. $C D$ values are determined from proteins in TNE buffer in the absence (black) or presence of DOPC/DOPS (light grey) or DOPC/DOPE (dark grey) vesicles. Values are mean \pm SD for three measurements. The line corresponds to ratio value of 1 , which is considered as the lower limit empirically used as a criterion of coiled-coil formation.

Fig.4. Lipid-binding of dystrophin multirepeat proteins. Representative data of (A) velocity sedimentation on sucrose density gradient and (B) gel-filtration chromatography, showing that proteins are recovered as protein-lipid complexes when in contact with DOPC/DOPS vesicles. Protein is placed in contact with DOPC/DOPS or DOPC/DOPE vesicles for 2 hours at $20^{\circ} \mathrm{C}$. Free protein is separated from protein-lipid complexes by one of the two methods. SDS-PAGE followed by Coomassie blue (A) or silver staining (B) is performed for protein detection.

Fig. 5. Conformational changes of the multirepeat proteins upon binding to lipid vesicles monitored by fluorescence. Intrinsic Trp fluorescence corrected spectra of proteins in TNE buffer in absence (black circles), or in presence of DOPC/DOPS (white circles) or DOPC/DOPE (white squares) vesicles at an excitation wavelength of $295 \mathrm{~nm}$. a. u. (arbitrary units).

Fig. 6. Schematic illustration of the lipid-binding domains of dystrophin and a new view of dystrophin in the muscle cell. (A) Dystrophin molecule and its identified partners. H1-4, hinges 1 to 4; $\mathrm{ABD} 1$ and $\mathrm{ABD} 2$, actin-binding domains 1 and 2; DGC, dystrophin-glycoprotein complex; LBD1 and LBD2, lipid-binding domains 1 and 2; "?" indicates the region of repeats 20-24 with partners that are not yet identified. (B) Dystrophin (purple) is represented in the cell context with its different partners (yellow). Lipid-binding domains closely attach dystrophin to the sarcolemma by interactions with the membrane phospholipids. Actin-binding domains interact with the cytoskeleton via $\gamma$-actin and Cys-rich domain and $\mathrm{C}$-terminal end interact with $\beta$-dystroglycan ( $\beta$-DG), $\alpha$-dystrobrevin-2 ( $\alpha$-DB2) and syntrophins (SYN). $\alpha$-DG, $\alpha$-dystroglycan; SGC/SPN, sarcoglycan / sarcospan complex. 
Table 1. Dystrophin multirepeat proteins used

\begin{tabular}{|c|c|c|c|c|}
\hline $\begin{array}{l}\text { Construct } \\
\text { (number of } \\
\text { residues) }\end{array}$ & $\begin{array}{c}\text { Start } \\
\text { residue }\end{array}$ & End residue & N-terminus & C-terminus \\
\hline R4-6 (338) & 718 & 1054 & $M^{*} \underline{\mathbf{S}}$ EIRKR $\ldots$ & ...EEQMNKLRKIQ \\
\hline R7-9 (339) & 1039 & 1376 & ${ }_{M} \mathrm{HCQKLEEQMN} .$. & ...EQSIQSAQETE \\
\hline R9-11 (323) & 1257 & 1578 & ${ }_{M}$ KCKTLEEVWWA... & ...E్CLKLSRKMRK \\
\hline $\mathrm{R} 10-12$ (327) & 1361 & 1686 & ${ }_{{ }_{1} \mathrm{RQKLLEQS} I Q} \ldots$ & ...LEYQKHMETFDQ \\
\hline $\mathrm{R} 11-15(513)^{\#}$ & 1461 & 1972 & ${ }_{G S} \mathbf{F Q K} \underline{P A N} \ldots$ & 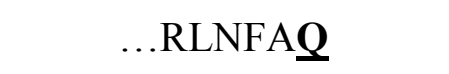 \\
\hline R12-14 (323) & 1562 & 1883 & ${ }_{{ } \mathrm{RKQQLEKCLKK} . .}$ & ...LEISHQWYQYK \\
\hline R14-16 (331) & 1780 & 2109 & $M(\underline{\mathrm{P}}) \mathrm{LKELEQF} \ldots$ & ... DR $\underline{\text { SVEKWRRF }}$ \\
\hline R14-17 (439) & 1780 & 2217 & $M(\underline{\mathrm{P}}) \mathrm{LKELEQF} \ldots$ & ...EEQKNILSEFQ \\
\hline R17-19 (329) & 2095 & 2422 & ${ }_{M}$ RQGRFDR $\underline{S} V E \ldots$ & $\ldots \mathrm{LLQELRA}^{* *}(\underline{\mathrm{K} Q P D L})$ \\
\hline
\end{tabular}

* R4-6 starts at the first residue of repeat 4 as there is hinge 2 before.

**R7-19 ends before the exact end of repeat 19 as there is a Proline residue and the hinge 4 after.

Residue in bold indicates the start ( $\mathrm{N}$-terminus column) or end (C-terminus column) residue of the repeat from the Winder alignment. ${ }^{24}$

Residue underlined indicates the start ( $\mathrm{N}$-terminus column) or end (C-terminus column) residue of the repeat from the Koenig alignment; ${ }^{23}$ when missing, it is underlined and in parentheses (Residue).

$G S$ or $M$ in italics indicate the residues left at the $\mathrm{N}$ terminus after cleavage of the tags.

${ }^{\#}$ the actin-binding domain described in this region is from residue $1416-1880^{6}$ 
Table 2. Trp fluorescence changes upon binding of proteins to DOPC/DOPS vesicles

\begin{tabular}{|c|c|c|c|c|}
\hline $\begin{array}{l}\text { Three-repeat } \\
\text { proteins }\end{array}$ & $\begin{array}{c}\text { Tryptophan residues per } \\
\text { repeat }\end{array}$ & $\begin{array}{c}\text { Number of } \\
\text { tryptophan } \\
\text { residues per } \\
\text { protein }\end{array}$ & $\begin{array}{c}\text { Fluorescence } \\
\text { maximum } \\
\text { wavelength }(\mathrm{nm}) \\
\text { without/with } \\
\text { binding to anionic } \\
\text { vesicles* } \\
\end{array}$ & $\begin{array}{c}\text { Fluorescence } \\
\text { increase on } \\
\text { binding to anionic } \\
\text { vesicles }\end{array}$ \\
\hline R4-6 & $\begin{array}{l}\text { R4 (3), R5 (1), } \\
\text { R6 (2) }\end{array}$ & 6 & $334 / 333$ & $180 \%$ \\
\hline R7-9 & $\begin{array}{l}\text { R7 (3), R8 (2), } \\
\text { R9 (4) }\end{array}$ & 9 & $337 / 335$ & $130 \%$ \\
\hline R11-15 & $\begin{array}{l}\text { R11 (0), R12 (4), } \\
\text { R13 (1), R14 (0), } \\
\text { R15 (2) }\end{array}$ & 7 & $331 / 330$ & $170 \%$ \\
\hline R12-14 & $\begin{array}{l}\mathrm{R} 12(4), \mathrm{R} 13(1), \\
\mathrm{R} 14(0)^{* *}\end{array}$ & 6 & 333 / 333 & $370 \%$ \\
\hline R14-17 & $\begin{array}{l}\mathrm{R} 14(0), \mathrm{R} 15(2), \\
\mathrm{R} 16(1), \mathrm{R} 17(5)\end{array}$ & 8 & 334 / 332 & $130 \%$ \\
\hline R17-19 & $\begin{array}{l}\text { R17 (5), R18 (2), } \\
\text { R19 (2) }\end{array}$ & 9 & $338 / 333$ & $150 \%$ \\
\hline
\end{tabular}

The underlined repeats (example, R11, (0)) contain no tryptophan residue.

* excitation wavelength is $295 \mathrm{~nm}$; spectra were fitted with a Gaussian curve to obtain an accurate determination of the maximum emission wavelengths

**a Trp residue from the $15^{\text {th }}$ repeat is situated in the C-terminal extension of this construct (see Table 1) 


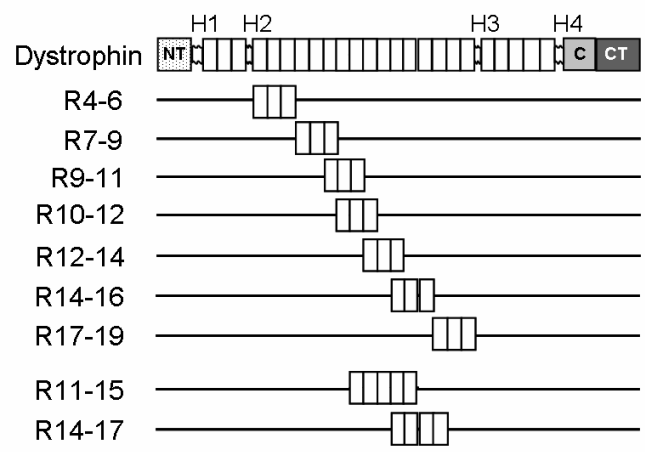

Fig. 1 

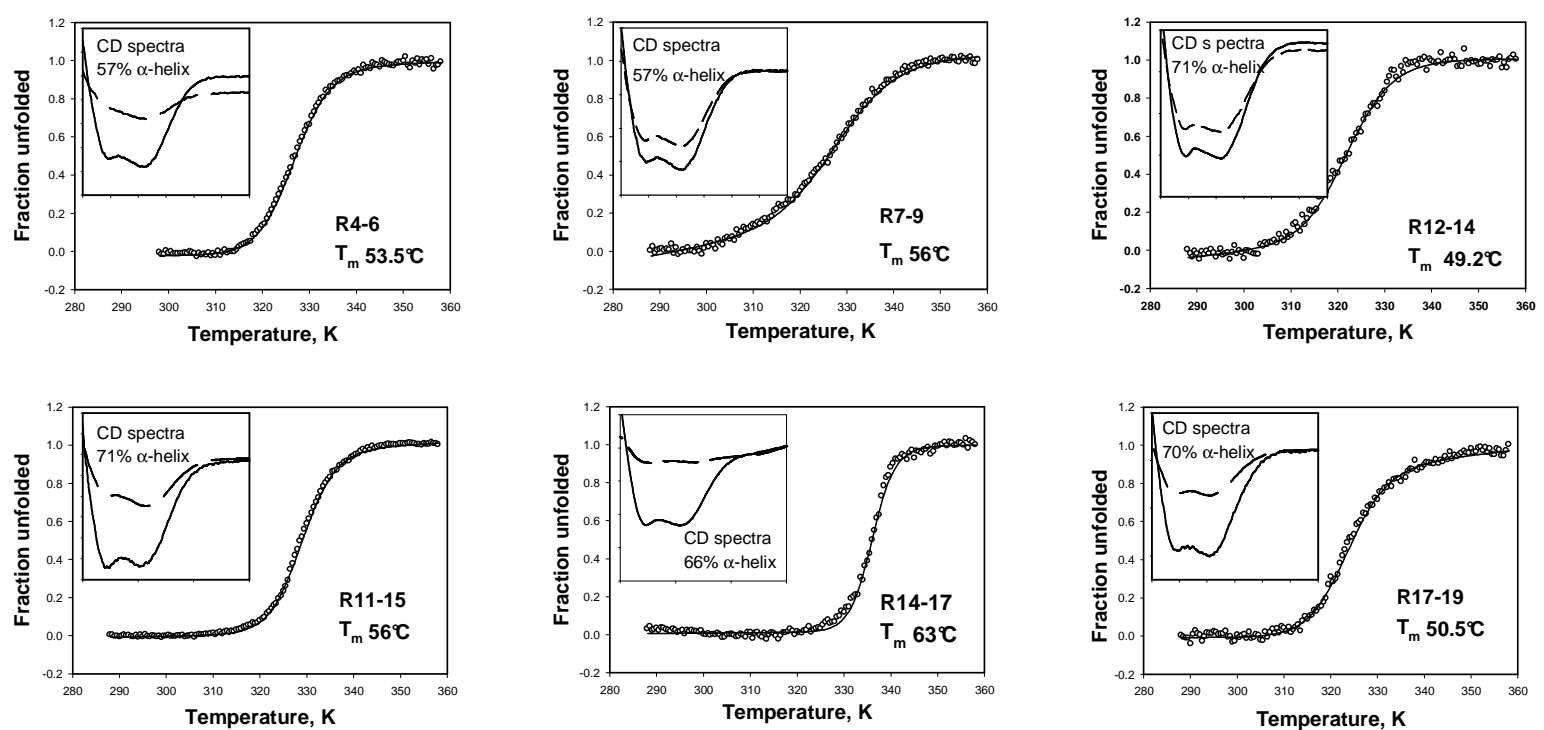

Fig. 2 


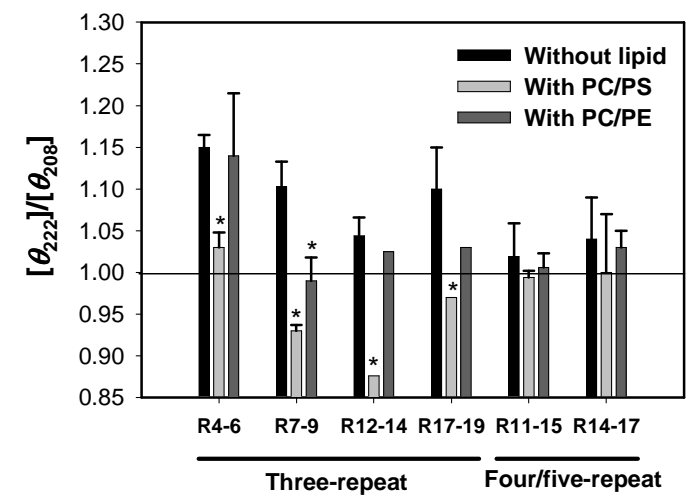

Fig. 3 
A

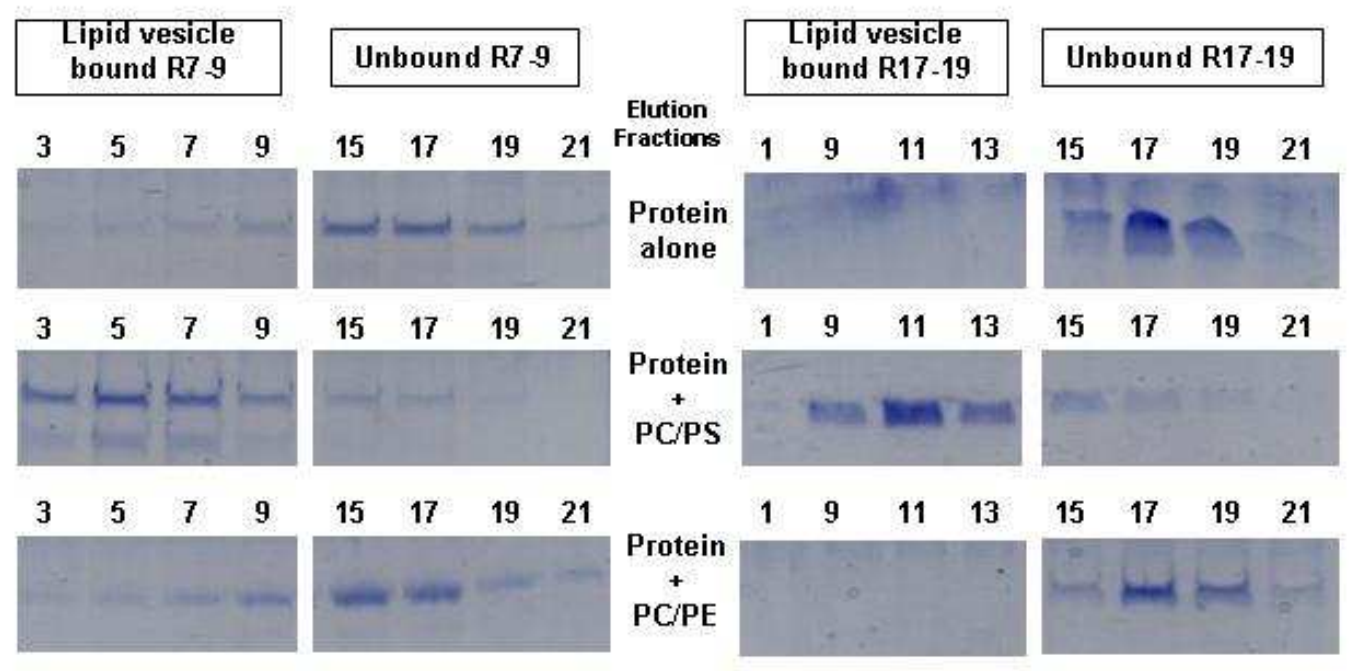

B

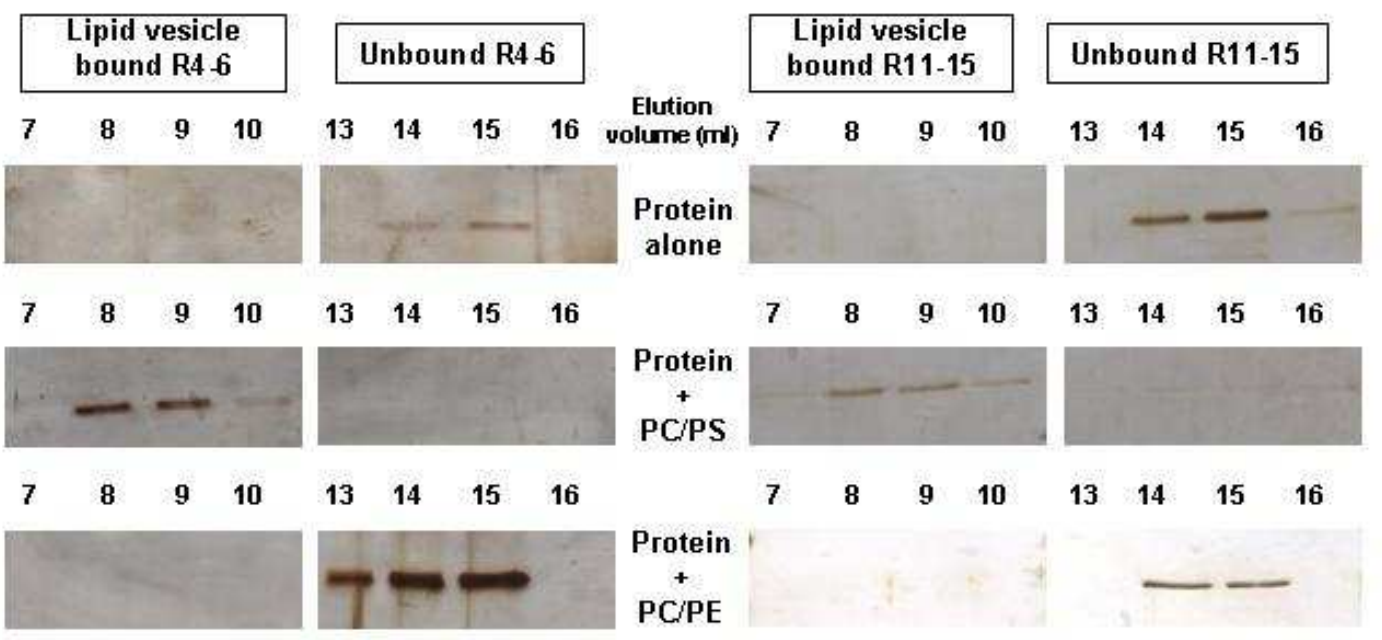

Figure 4 

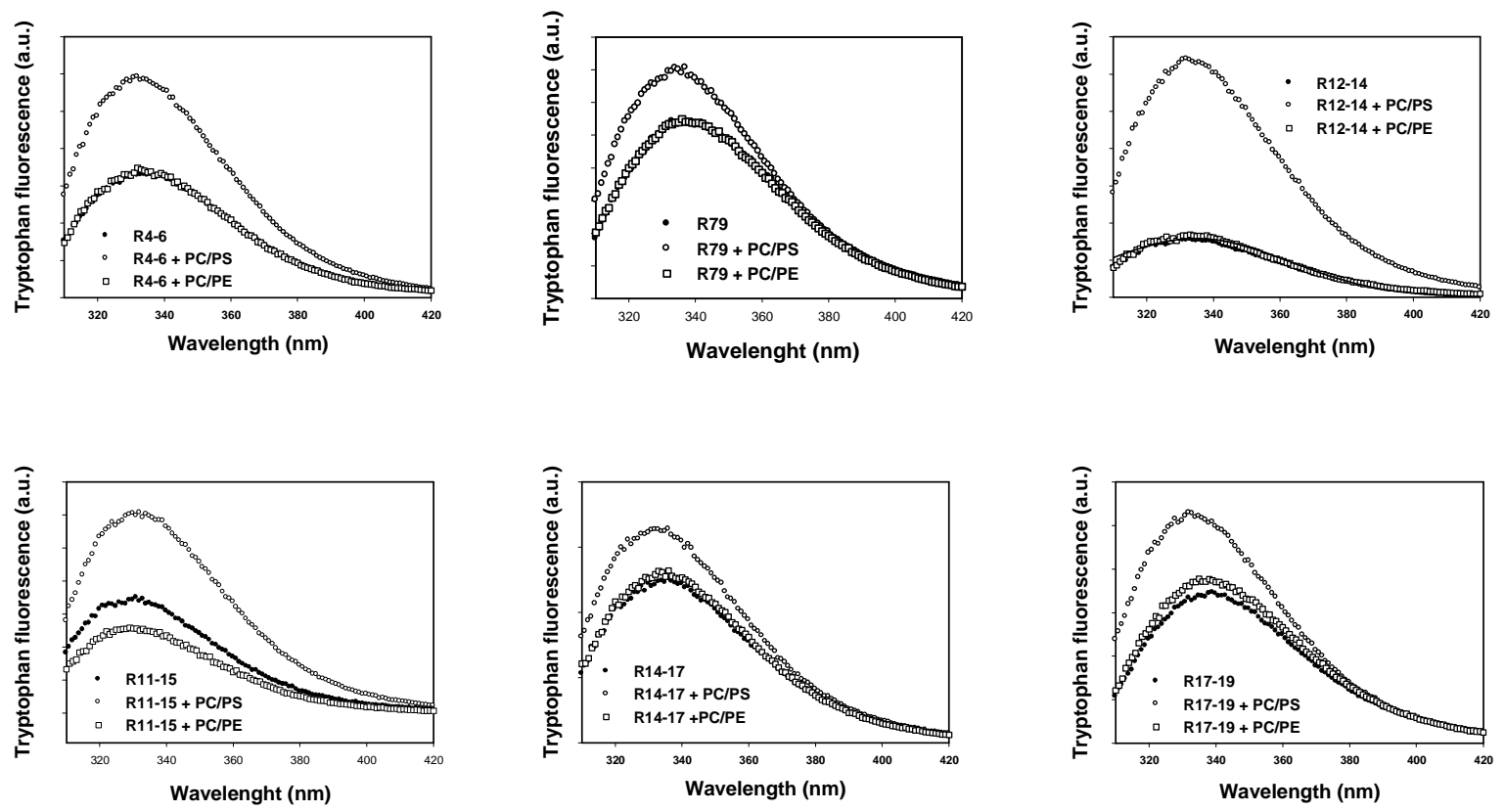

Fig. 5 
A

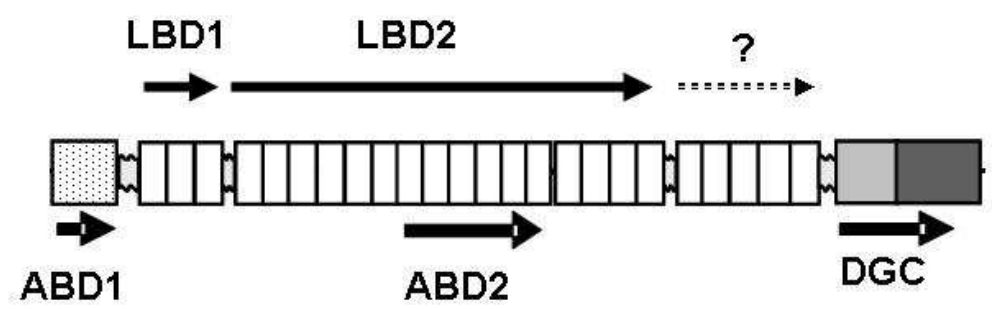

B

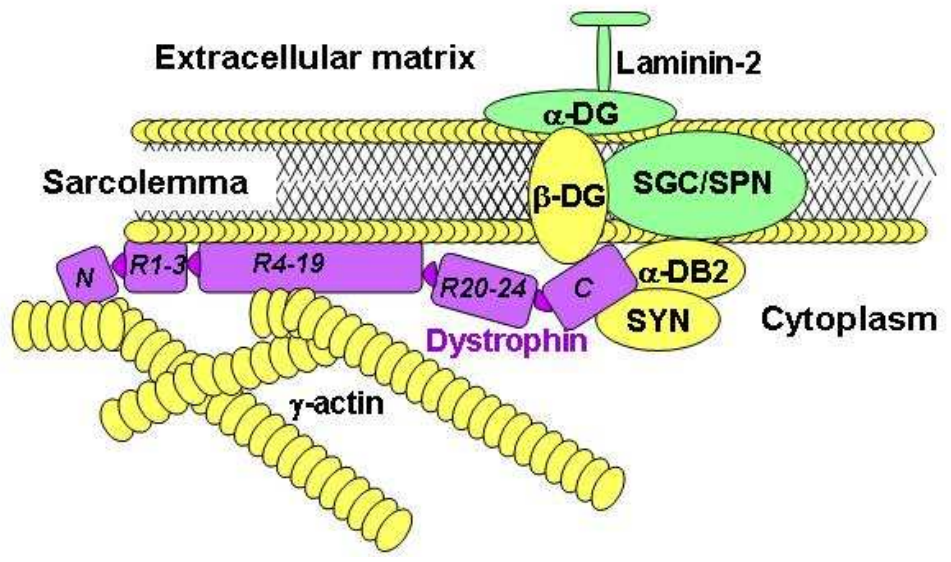

Fig. 6 